\title{
PESSOAS EM SITUAÇÃO DE RUA NO BRASIL: A RELAÇÃO ENTRE O PODER ESTATAL E A (IM)POSSIBILIDADE DE ACESSO A DIREITOS
}

\author{
Antonio Matheus Sardinha Santos ${ }^{1}$ \\ Sandra Suely Moreira Lurine Guimarães ${ }^{2}$
}

\begin{abstract}
Resumo: Este artigo discute, de forma interdisciplinar, como é possível, em um Estado Democrático de Direito, existir formas de vida expostas às mais diversas possibilidades de violações de direitos e garantias fundamentais, como as das pessoas em situação de rua no Brasil. O objetivo deste artigo é mostrar como se deu o início do problema das pessoas em situação de rua no país e como o Estado brasileiro enxerga a questão, e a partir disso refletir como o acesso a direitos impede que estes indivíduos detenham participação na sociedade. Assim, se tratará a hipótese de que as pessoas em situação de rua, do ponto de vista do Estado, por não habitarem o contexto político, econômico e social de forma efetiva não são tratados como seres sujeitos de direitos na ordem pública, o que legitima tomada de decisões que são, em parte, danosas a esta classe e cobertas por um véu falacioso de cuidado com este contingente populacional. Para sustentar e desenvolver este artigo foi utilizada uma metodologia de pesquisa que analisa como se deu a formação da questão no contexto sóciopolítico brasileiro, bem como uma abordagem crítica das bases normativas instituídas em torno da problemática. Ainda, se utilizou das contribuições bibliográficas de autores que escrevem sobre: politização da vida, poder estatal e relações sociais, tais como Michel Foucault, Giorgio Agamben e Achille Mbembe.
\end{abstract}

Palavras-chave: Pessoas em situação de rua. Poder estatal. Politização da vida. Impossibilidade de acesso a direitos.

\begin{abstract}
This article discusses, in an interdisciplinary way, how it is possible, in a Democratic State of Rights, to have life forms exposed to the most diverse possibilities of violations of fundamental rights and guarantees, such as those of the homeless in Brazil. The purpose of this article is to show how the problem of homeless people in the country began and how the Brazilian State sees the issue, and from that to reflect on how access to rights prevents these individuals from participating in society. Thus, the hypothesis that people on the street, from the point of view of the State, because they do not inhabit the political, economic and social context effectively, will not be treated as beings subject to rights in public order, which legitimizes making decisions that are, in part, harmful to this class and covered by a fallacious veil of care with this contingent population. To support and develop this article, a research methodology was used that analyzes how the issue was formed in the Brazilian socio-political context, as well as a critical approach to the normative bases instituted around the problem. Still, it used the bibliographic contributions of authors who write about: politicization of life, state power and social relations, such as Michel Foucault, Giorgio Agamben and Achille Mbembe.
\end{abstract}

Keyword: Homeless people. State power. Politicization of life. Impossibility of access to rights.

\footnotetext{
${ }^{1}$ Graduando em Direito pela Faculdade Faci Wyden. Currículo Lattes: http://lattes.cnpq.br/7035238688938420.

${ }^{2}$ Doutora em Ciências Sociais pela UFPA, Mestre em Sociologia pela UFPA, Bacharel em Filosofia pela UFPA, Bacharel em Direito pelo Centro Universitário do Pará. Currículo Lattes: http://lattes.cnpq.br/5446022928713407.
} 


\section{Introdução}

Atualmente no Brasil existem mais de 210 milhões de pessoas, segundo o Instituto Brasileiro de Geografia e Estatística (IBGE) ${ }^{3}$, dentre as quais existem mais de 100 mil pessoas em situação de rua, de acordo com o último levantamento feito pelo Instituto de Pesquisa Econômica Aplicada (IPEA), realizado em 2017. É importante frisar que, este número de pessoas que estão nas ruas inclui homens, mulheres, crianças, idosos, pessoas da comunidade LGBT, ex-detentos, entre outros, os quais se encontram nesta situação pelas mais variadas razões. Isto evidencia o caráter heterogêneo da questão e, ao que tudo indica, este problema social se tornou ainda mais acentuado com a entrada de mais de 30 mil venezuelanos ${ }^{4}$ no país após a crise humanitária da Venezuela (estimativa realizada pelo IBGE em 2018) consequentemente, essas pessoas passaram a agregar o contingente populacional existente nas ruas até então, ou seja, reforçando ainda mais a complexidade do problema.

Medidas estatais devem conter uma complexidade em suas articulações que seja proporcional ao problema a que se destinam. Sendo o Estado, e aqueles que o representam, o(s) detentor(es) do monopólio das ferramentas necessárias para implementar tais mudanças, pode-se dizer que o Estado tem o poder de decidir quem terá prioridade de tratamento e quem permanece invisível. É seguro afirmar que as políticas públicas atuais que são voltadas para a mitigação do problema das pessoas em situação de rua são extremamente fracas, obsoletas e sem toda a complexidade que demanda o problema, mesmo que elas tenham sido criadas após a emissão do decreto presidencial $n^{\circ} 7.053 / 2009$, o qual estabelecia diretrizes para a política nacional para população em situação de rua. Tal decreto contém pontos que não são adequadas à solução do problema, ou mesmo sua mitigação.

A ineficácia estatal na tratativa da questão fica clara quando se constata que os dados demonstram a quantidade de pessoas em situação de rua antes e depois da emissão do decreto. Estes dados revelam que, antes do decreto existiam cerca de 30 mil pessoas em situação de rua $^{5}$ e após a emissão dele o número de pessoas nesta situação aumentou para mais de 100 mil indivíduos ${ }^{6}$. Ou seja, após a introdução de uma estratégia governamental formulada

\footnotetext{
${ }^{3}$ Disponível em: https://www.ibge.gov.br/apps/populacao/projecao/box_popclock.php. Acesso em: 11/10/2020.

4 Estimativa realizada pelo IBGE. Disponível em: https://www.osul.com.br/ibge-aponta-que-308-milvenezuelanos-vivem-no-brasil-ha-3-anos-eram-mil/. Acesso em: 12/10/2020.

${ }^{5}$ Dado emitido pela Revista Aprendendo a Contar, sob orientação do Ministério de Desenvolvimento Social e Combate à Fome em 2009. Disponível em: https://www.mds.gov.br/webarquivos/publicacao/assistencia_social/Livros/Rua_aprendendo_a_contar.pdf Acesso em: 12/10/2020.
}

6 De acordo com o último censo feito pelo IBGE. Disponível em: http://www.ipea.gov.br/portal/index.php?option=com_content\&view=article\&id=29303. Acesso em: 12/10/2020. 
unicamente para a tentativa de mitigação e resolução do problema o que se vê é exatamente o oposto, houve mais do que a triplicação do contingente populacional existente nas ruas em menos de uma década.

Para Michel Foucault (1976), Estado (soberano), por excelência, detém a prerrogativa de ditar a vida em sociedade, nele está contido, em grande parte, o poder de decisão sobre quem vive e quem morre. Quem deve morrer e quem poder viver. "Por isso, matar ou deixar viver constituem os limites da soberania, seus atributos fundamentais. Ser soberano é exercer o controle sobre a mortalidade e definir a vida como a implantação e manifestação do poder." (MBEMBE, p.5, 2018). Diante deste cenário, portanto, torna-se importante compreender a questão das pessoas em situação de rua no Brasil não apenas como uma mera anomalia social naturalizada no cotidiano do país e que está sendo regida por medidas ineficazes, mas mais do que isso, devemos enxergar esta problemática como um infeliz exemplo material de como o soberano decide, por meios governamentais, quem deve viver e quem não, quem tem acesso a direitos e quem não, quem participa da vida em sociedade e quem não.

Tendo isto em vista, faz-se necessário discutir, sob um viés interdisciplinar, dada a complexidade da questão, a necessidade da indagação: como pode em um Estado Democrático de Direitos, como o Brasil, existir formas de vida sem nenhum direito constitucional respeitado, tal como as pessoas em situação de rua? E mais, discutir como o Estado utiliza seus mecanismos (poder) para gerir a vida em sociedade, possibilitando que uma parcela relevante de indivíduos fique à margem de qualquer proteção e acesso à direitos. Para que seja possível uma compreensão teórica e material da questão, trilharemos um caminho argumentativo que parte da formação do problema no contexto social, passando pela função atribuída ao Estado frente a problemática e a atuação externada por ele, chegando a reflexão sobre a condição a que estas pessoas estão submetidas até a abordagem sobre quais medidas se fazem precípuas para a tentativa de resolução da problemática.

\section{Surgimento do fenômeno das pessoas em situação de rua no país}

É de suma importância ressaltar que, o principal elemento que pode ser utilizado para destacar um fenômeno social tão perceptível como este é a exclusão econômica. Por mais que outros fatores também influenciem na perpetuação do problema. E quando se fala sobre exclusão econômica em um contexto como o social-brasileiro, é indispensável partir do ponto que sustentou o país por séculos: a escravidão. O contexto superveniente a exploração forçada de corpos no Brasil é marcado por ordenamentos que legitimavam separações, 
estigmatizações e vulnerabilidades, portanto: exclusão econômica ${ }^{7}$. E isso nos serve para análise das pessoas em situação de rua no contexto atual, como estipula Silvio Almeida (2019, p.192):

Sem distribuição de renda, a industrialização e o aumento da produção tornaram-se expressões da modernização conservadora, que, em nome da manutenção da desigualdade e da concentração de renda, exigiram a supressão da democracia, da cidadania e a ocultação dos conflitos sociais, inclusive os de natureza racial.

O pós abolição trouxe ares de modernização do país, econômica e socialmente. Portanto, deve-se refletir acerca das formas de industrialização e modernização das cidades, como se deram, quais mecanismos foram adotados e quais pessoas- ou classes- estavam a frente dessas tomadas de decisão, desses polos de poder. Quem representavam? O que buscavam para o país em um contexto pós abertura formal das senzalas? A partir da formação das cidades é onde está inscrito o vínculo prévio para o aparecimento do fenômeno das pessoas em situação de rua e, consequentemente, este fator agregado ao modelo econômico adotado pelas cidades incorreu na intensificação do problema. O processo de urbanização em países subdesenvolvidos- e de passado colonial- como o Brasil se dá através da industrialização das suas cidades, contudo, aliado à industrialização subsiste uma característica bastante comum ao processo, que é a mercantilização das terras que compõem o espaço urbano, movimento este que acarreta disputas, consequentemente, aqueles destituídos de poderio econômico ficam "à deriva".

Desta forma, o aparecimento das pessoas em situação de rua se deu em um cenário urbano que decorre de um processo histórico composto de situações de segregação sociopolítica-espacial, traduzido na monopolização do espaço urbano pelo modelo econômico vigente nas cidades (durante os processos de urbanização e metropolização do país) e pelas classes que detinham poder durante a escravidão e após o seu fim (no final do século XIX). Como o sociólogo brasileiro Jessé Souza (2019, p.57) comenta:

Já no contexto da incipiente urbanização e modernização do século XIX, em algumas grandes cidades, temos um passo importante nesse processo que se consolida com a formação de uma classe média moderna e diferenciada no século XX. Sua função de capataz da elite, no entanto, é preservada em algumas funções modernizadas. As frações mais conservadoras assumirão, como função sua, por exemplo, a manutenção da distância social em relação aos setores populares.

\footnotetext{
${ }^{7}$ A exemplo a Lei de Terras de 1850, a qual extinguia a apropriação de terras com base na ocupação e dava ao Estado a prerrogativa de distribuí-las somente mediante compra. Dessa maneira, ex-escravizados tinham grandes restrições, pois, somente podia se tornar proprietário aqueles que detinham grandes quantias.
} 
Por consequência desta monopolização dos espaços urbanos, a rua se torna o único lugar acessível e disponível que o contingente segregado pelo modelo econômico tem como possibilidade de sobrevivência e autossuficiência. Logo, dentro do curso deste processo de formação das cidades e os seus modelos econômicos, não só as zonas em que ocorrem a maior parte das relações sociais de poder são negadas às pessoas com baixo poderio monetário mas a própria rua também se torna um local de disputa entre o modelo econômico vigente e as pessoas que foram excluídas das áreas mercantilizadas no processo de industrialização do país.

Assim, proveniente deste sistema, acabam surgindo indivíduos cujo os meios de acesso básico a direitos fundamentais, como saúde, alimentação, educação e moradia se tornam inviáveis, haja vista que, tais indivíduos são postos em uma zona de estigma na sociedade em decorrência deste processo competitivo de monopolização dos espaços sociais implantado nas cidades, como assim considera o sociólogo Erving Goffaman (1891, p.8) ao preconizar que:

Por definição, é claro, acreditamos que alguém com um estigma não seja completamente humano. Com base nisso, fazemos vários tipos de discriminações, através das quais efetivamente, e muitas vezes sem pensar, reduzimos suas chances de vida: Construímos uma teoria do estigma; uma ideologia para explicar a sua inferioridade e dar conta do perigo que ela representa, racionalizando algumas vezes uma animosidade baseada em outras diferenças, tais como as de classe social.

Ou seja, este processo de mercantilização das áreas urbanas, fruto da industrialização acelerada do país, funciona como o fator principal da ação de segregação socioespacial, reproduzindo indivíduos de baixa renda monetária ou nenhuma, que estarão suscetíveis a diversas banalizações e violações de direitos devido a sua posição de subalternização dentro da estrutura social, tal como as pessoas em situação de rua. Então, através disso é possível afirmar que a população em situação de rua é um reflexo do modo de vida adotado pelo cenário urbano durante e após os processos de industrialização, mercantilização e estruturação econômica das cidades e do país na sua totalidade.

\section{O Estado como responsável por materializar os direitos previstos na Constituição}

O artigo $6^{\circ}$ da Constituição Federal de 1988 assegura que são direitos sociais a educação, a saúde, a alimentação, o trabalho, a moradia, o transporte, o lazer, a segurança, a 
previdência social, a proteção à maternidade e à infância e a assistência aos desamparados, ou seja, são direitos fundamentais que devem ser materializados pelo Estado a todos os cidadãos, dada a sua obrigação dentro da relação vertical sociedade e governo. Dentro desses aspectos, o Estado como um todo- o que abarca todos os entes federados - é o principal responsável por promover ações para a concretização dos dispositivos previstos na Carta Magna, e o principal corpo responsável também por impedir que haja a violação dessas disposições pela sociedade ou por ele mesmo.

Desta forma, sempre que problemas sociais surgirem é de total responsabilidade estatal a elaboração e implementação de métodos que sejam destinados a resolução da problemática. E esta ideia se torna necessária quando se analisa a questão das pessoas em situação de rua no país, já que como já demonstrado, após a formação das cidades, principalmente as grandes metrópoles, os modelos econômicos nelas implantados e por elas adotados trouxe, como consequência quase que inevitável, uma grande segregação socioespacial de pessoas, e com isso uma grande gama de indivíduos sem o mínimo para sobrevivência. Logo, nasce a necessidade de uma ação positiva governamental, ou seja, criando políticas públicas com o fim de garantir- materialmente- o acesso à direitos por parte desta classe de indivíduos e que enseje uma estratégia de retirada destes desta zona de hipossuficiência e que os coloque de volta as relações sociais, essa deve ser entendida como a função do Estado, por excelência.

Tendo isto em vista, em 2009 foi emitido o decreto presidencial $\mathrm{n}^{\circ} 7.053$, estabelecendo diretrizes para a política nacional para as pessoas em situação de rua no país, contendo orientações de como seria feita e articulada a estratégia estatal para a tentativa de resolução do problema, tais como: identificação da população em situação de rua, a implementação desta política nacional de forma descentralizada, necessidade de pesquisa e divulgação de dados que correspondem ao problema, dentre outros aspectos. Ou seja, uma tentativa do Estado de resolver o problema social que se instaurou, para que assim, seja possível a materialização dos direitos previstos na Constituição para este grupo vulnerável socialmente e, consequentemente, retirando dele o estigma social.

Contudo, o acompanhamento dos efeitos que qualquer medida governamental gera é de suma importância, pois, só com a monitoração das consequências da estratégia estatal é que será possível ter a real compreensão do tamanho do impacto que ela produziu, a fim de se averiguar se eles foram positivos ou negativos. Ainda, isso é importante porque permite uma análise crítica dos procedimentos que se materializam ao decorrer do processo de 
movimentação estatal, ocasião em que é possível questionar se estas movimentações estatais efetivamente são voltadas à mitigação dos problemas a que se propõem. A este respeito, o filósofo Giorgio Agamben (2003, p.12), ao abordar a função política do Estado, ressalta:

Somente erguendo o véu que cobre essa zona incerta poderemos chegar a compreender o que está em jogo na diferença- ou na suposta diferença- entre o político e o jurídico e entre o direito e o vivente. E só então será possível, talvez, responder à pergunta que não para de ressoar na história da política ocidental: o que significa agir politicamente?

E como já exposto, houve mais do que a triplicação do número de pessoas em situação de rua no país após a emissão do decreto e da implementação da sua política nacional, aumento compreendido entre 2009 e 2017. Então, com este aumento exponencial do problema se faz necessária uma nova análise da questão, tendo que se considerar quais pontos do decreto não surtiram os efeitos que se esperava e quais novas estratégias são agora necessárias, já que, com a evidente ineficácia da política atual (vista nos números), outras medidas terão de ser adotadas. Ainda, colocar em grau de reflexão o que está por trás das movimentações governamentais. O soberano realmente tem tentado garantir direitos às pessoas que se encontram nas ruas?

\section{Pessoas em situação de rua e o status social}

É seguro afirmar que, nos Estados modernos todas as ações e decisões governamentais acerca de matérias específicas da sua sociedade irão ter, logicamente, um impacto significativo e substancial no que tange as relações sociais de poder, ou seja, o Estado toma decisões que obrigatoriamente serão vinculatórias à sociedade. E esta característica das decisões estatais aumenta a incidência de atitudes políticas dentro da relação hierárquica de poder entre os cidadãos e o Estado, de modo que, neste eixo, todas as movimentações feitas pelo Estado irão, necessariamente, ter que considerar e observar tanto a importância do papel dos seres sociais quanto os possíveis impactos mesmos. Michel Foucault (1997, p.213-234), no início do século XX, preconizou esta alta inserção da vida natural do homem nos cálculos de poder do Estado como biopolítica. É em essência o domínio da vida sobre o qual o poder (do soberano) estabeleceu o controle. Desta forma, ao se considerar válidos e legítimos os cálculos governamentais que impactaram a vida do ser, consequentemente, se aceita a posição de soberania estatal. Com isso, através da implantação de suas decisões, o próprio ente 
soberano pode imputar a algumas formas de vida um caráter subjugado e de menor importância dentro da sociedade, rotulando-as; por vezes, no contexto social.

A atribuição de um caráter menos importante, por parte do Estado, a alguma classe de indivíduos pode ser justificada por um aspecto meramente político, e claro, legitimado e possibilitado pela biopolítica. Ou seja, determinada classe da sociedade pode representar, sob o ponto de vista do Estado, uma ameaça a estabilidade de um determinado governo. Para tanto, o governo pode criar medidas e estratégias, dentro de uma determinada zona de atividade, com o único intuito de acabar com o problema ou com esta "ameaça", assim, nesta zona de atividade o governo pode modificar as normas ou simplesmente suspendê-la com a exclusiva intenção de legitimar e validar quaisquer medidas que se fizerem necessárias para pôr termo ao problema ou a ameaça.

O filósofo político Giorgio Agambem (1995, p.26) conceitua esta zona de atividade estatal como "estado de exceção", e determina que esta exceção estatal ou como ele se refere em sua obra, exceção soberana:

É, neste sentido, a localização fundamental, que não se limita a distinguir o que está dentro e o que está fora, a situação normal e o caos, mas traça entre eles um limiar (o estado de exceção) a partir do qual interno e externo entram naquelas complexas relações topológicas que tornam possível a validade do ordenamento.

Ou seja, em um estado de exceção as ameaças ao governo estão dentro e fora, concomitantemente, dos cálculos estatais de poder, pois, o "soberano" considera sim essas ameaças ou esses problemas como um elemento integrador das suas políticas, porém, ele as considera para, após isso, desconsiderá-las ou eliminá-las através de medidas e estratégias exclusivas para tanto. Assim, Agamben (2003, p.11-13) diz:

O estado de exceção constitui um ponto de desequilíbrio entre direito público e fato político...O totalitarismo moderno pode ser definido, nesse sentido, como a instauração, por meio do estado de exceção, de uma guerra civil legal que permite a eliminação física não só dos adversários políticos, mas também de categorias inteiras de cidadãos que, por qualquer razão, pareçam não integráveis ao sistema político. O estado de exceção apresentase, nessa perspectiva, como um patamar de indeterminação entre democracia e absolutismo.

Consequentemente, este estado de exceção pode criar e dar forma a vidas sem quaisquer direitos respeitados e assegurados, haja vista que, essas vidas podem ser vistas pelo "soberano" como uma ameaça ao seu status quo. Esta ideia se aproxima, atualmente, ao contingente populacional existente nas ruas (mais de 100 mil pessoas), pois, se materializa 
como uma anomalia social demasiadamente alarmante que, obviamente, gerará mediadas estatais. Nesta perspectiva, a biopolítica ${ }^{8}$ possibilita que vidas sejam esquadrinhadas e controladas em seus mais diversos aspectos e em sua totalidade, de forma a possibilitar que, medidas voltadas a supressão humana pelo ente estatal tornem-se legitimas se implementadas através de atos institucionais.

Agamben vai denominar estas vidas existentes no estado de exceção como "vidas matáveis" ou "vidas sem valor", já que, o próprio ente soberano as desqualifica por entendêlas como parte integrante de uma ameaça. Algo que deve ser entendido como uma nefasta consequência da politização da vida, pois, a partir do momento que a vida natural do homem passa a se envolver cada vez mais com a política estatal, é possível que haja, muitas vezes, a criação de conflitos entre eles, conflitos esses que são sanados; por vezes, através de decisões absurdas. Agamben (1995, p.146) diz que:

É como se toda valorização e 'politização' da vida (como está implícita, no fundo, na soberania do indivíduo sobre a sua própria existência) implicasse necessariamente uma nova decisão sobre o limiar além do qual a vida cessa de ser politicamente relevante, é então somente 'vida sacra' e, como tal, pode ser impunemente eliminada.

Assim, o estado de exceção funciona como uma ferramenta crucial para que o soberano consiga implementar sua governabilidade por meio do poder sobre a vida. Sempre que alguma ameaça à estabilidade deste poder surgir, será possível desenvolver uma medida a fim de impor termo ao problema, e o ordenamento jurídico oferece guarida para o poder sobre a vida de que detém o soberano. "Na verdade, o estado de exceção não é exterior nem interior ao ordenamento jurídico e o problema de sua definição diz respeito a um patamar, ou a uma zona de indiferença, em que dentro e fora não se excluem mas se indeterminam." (AGAMBEN, p.39, 2003) Considerar a vida a ser eliminada como parte integrante do sistema biopolítico é a peça principal da governabilidade do soberano. O domínio sobre a vida é o pilar de uma exceção estatal, dentro dela se diminui a relevância política da vida para que se torne "vida sacrificável” e seja impunemente dizimada. É o Estado (soberano) fazendo viver e deixando morrer. E isto torna-se possível por conta da grande inserção da vida do homem na política que permeia os Estados atualmente, a biopolítica.

\section{O Estado e a relação de inimizade com as pessoas em situação de rua}

\footnotetext{
${ }^{8}$ Por biopolítica, Foucault vai descrever o movimento segundo o qual, no início do século XVIII, a vida biológica do ser começa a se converter em objeto da política.
} 
Como já afirmado, há preceitos constitucionais que preveem a seguridade de direitos sociais aos cidadãos, os quais necessitam da atuação do Estado para serem materializados, a exemplo do artigo $6^{\circ}$ da Constituição Federal. Isto imputa ao soberano a necessidade de ações positivas que possam atribuir a todos os seres sociais, sem discriminações, a efetividade dos seus direitos. Só que isto leva a questionar o porquê ainda hoje existem mais de 100 mil pessoas ocupando uma zona da sociedade sem qualquer direito materializado, respeitado ou assegurado, como as pessoas em situação de rua?

Este questionamento só começa a fazer sentido quando se parte do ponto de vista biopolítico e do conceito de vida matável, já que, este contingente populacional existente nas ruas atualmente decorre, notadamente, de práticas estatais, portanto, de decisões políticas, principalmente durante a formação das cidades. Demais disso, o processo de urbanização e industrialização no Brasil, gerou uma grande repartição social em castas e uma segregação socioespacial nas cidades. Consequentemente, uma resposta às necessidades e hipossuficiências das castas mais baixas se tornaram, no decorrer do tempo, uma grande cobrança em face do Estado ("soberano").

Porém, a comparação entre os dados sobre o problema discutido, revela que tanto no passado, quanto atualmente demostra que o Estado não está verdadeiramente comprometido em chegar a uma resolução da questão. Isto porque houve mais do que a triplicação do número de pessoas nesta situação em menos de uma década. É a partir desse ponto que devemos pensar na questão das pessoas em situação de rua no Brasil sob a percepção do necropoder. Para Mbembe (2018, p.17), “o estado de exceção e a relação de inimizade tornaram-se a base normativa do direito de matar.". É importante ressaltar que, a eliminação de uma ameaça governamental dentro de um estado de exceção não necessariamente será o extermínio físico direto, tal como foi feito com os judeus na Alemanha Nazista ${ }^{9}$, mas pode ser sem sombra de dúvidas um extermínio velado- materializado pela falta de políticas públicas eficazes que cada vez mais segregam a "ameaça".

O soberano estabelece esta relação de inimizade dentro da estrutura necropolítica por diversos aspectos, e quando trata-se da questão das pessoas em situação de rua no Brasil podemos considerar alguns deles: I) Os seres existentes nas ruas configuram um grupo de pessoas apartados das relações políticas, econômicas e sociais; II) A ausência desses indivíduos em polos políticos, sociais e econômicos faz com que aqueles que detém o poder

\footnotetext{
${ }^{9}$ Ver Hannah Arendt. Eichmann em Jerusalém- Um relato sobre a banalidade do mal. Nesta obra, a filósofa Hannah Arendt analisa a logística de funcionamento dos campos de concentração nazistas. Acompanhando o julgamento de um dos mais lembrados autômatos -indivíduos agem sem pensar, apenas cumprindo ordens- de Hitler (Eichmann), Arendt descreve como a máquina alemã de matar funcionava e se perpetuou.
} 
governamental não tenham interesse em protegê-los; III) O problema social decorrente da não proteção estatal a esses seres gera cobranças substanciais (abalando o status quo do poder) e; IV) Paralelamente, a inércia soberana frente a questão tem reflexos em como a própria sociedade trata esses indivíduos, ou seja, a absoluta naturalização da condição degradante a que estas pessoas ficam submetidas. É como se as pessoas em situação de rua passassem a representar, agora, tanto uma ameaça ao poder soberano quanto a seus pares sociais. Mbembe (2018, p.20), considera:

A percepção da existência do outro como um atentado contra minha vida, como uma ameaça mortal ou perigo absoluto, cuja eliminação biofísica reforçaria meu potencial de vida e segurança, é este, penso eu, um dos muitos imaginários de soberania, característico tanto da primeira quanto da última modernidade.

Então, pode-se dizer que, o soberano começa a tratar as pessoas em situação de rua como uma espécie de inimigo interno do Estado, o qual desestabiliza o poder, e por isso, pode ser eliminada impunemente (uma mera vida matável). E a sociedade, através da falta de alteridade, compactua com esta política da morte, onde a ausência (intencional) do fornecimento de meios para sobrevivência é dirigida as pessoas que se encontram nas ruas. Achille Mbembe (2018, p.62), ressalta que:

Mais radicalmente, o horror experimentado sob a visão da morte se transforma em satisfação quando ela ocorre com o outro. É a morte do outro, sua presença física como um cadáver, que faz o sobrevivente se sentir único. E cada inimigo morto faz aumentar o sentimento de segurança do sobrevivente.

O interesse do soberano em matar seus inimigos não deve ser entendido como uma simples gama pela morte. É, antes de tudo, uma característica inerente de um estado de exceção e da necropolítica. A falta de uma verdadeira política pública (eficaz) destinada as pessoas em situação de rua pode ser entendida como a medida soberana destinada a morte política da ameaça ao status quo. Esta é a relação de inimizade estabelecida pelo Estado. "Matar é, portanto, reduzir o outro e a si mesmo ao estatuto de pedaços de carnes inertes, dispersos e reunidos com dificuldades antes do enterro" (MBEMBE, p.64, 2018). Portanto, uma morte política.

\section{A naturalização da condição de vida matável}


A condição degradante a que as pessoas em situação de rua estão submetidas é naturalizada em duas vertentes: I) o Estado, inerte diante ao assombro número de indivíduos nessa condição, ao implementar políticas sem eficácia, naturaliza a condição social desses seres. É necessária a naturalização da característica de vida matável no sistema necropolítico, pois, com isso há "perda de um 'lar', perda de direitos sobre seu corpo e perda de estatuto político" (MBEMBE, p.27, 2018) e; II) A naturalização realizada pelo Estado faz com que a própria sociedade adquira um papel central na eliminação da ameaça interna. Mbembe (2018, p.59) diz:

Se o poder ainda depende de um controle estreito sobre os corpos (ou de sua concentração em campos), as novas tecnologias de destruição estão menos preocupadas com a inscrição de corpos em aparatos disciplinares do que em inscrevê-los, no momento oportuno, na ordem da economia máxima, agora representada pelo "massacre".

A política da inimizade estabelecida pelo Estado- soberano- contra as pessoas em situação de rua também terá guarida na sociedade. O ódio, a indiferença e o desejo de eliminação serão estendidos a sociedade. No Brasil são vários e lamentáveis os casos em que pessoas nesta situação de vulnerabilidade, são vítimas das mais diversas formas de violência, inclusive, de homicídios, praticados não só por policiais, mas também por pessoas da sociedade civil. A exemplo, em Maceió- Alagoas entre 2010 e 2012, 73 moradores de rua foram assassinados ${ }^{10}$. Em São Paulo, durante a época da Copa do Mundo de 2014, realizada no Brasil, o Centro Nacional de Defesa dos Direitos Humanos da População em Situação de Rua e Catadores de Materiais Recicláveis - CNDDH- recebeu denúncias sobre a retirada forçada de pessoas em situação de rua de logradouros próximos a estádios de futebol ${ }^{11}$, uma espécie de política higienista sendo posta em prática. Mais recentemente, em agosto de 2020, cinco pessoas em situação de rua morreram em decorrência do frio na cidade de São Paulo, de acordo com o Movimento da População de Rua do Estado de São Paulo ${ }^{12}$. Como pode ser visto estes fatos, senão como as consequências da naturalização da condição de vida matável imposto pelo instrumento necropolítico do soberano?

O Ministério da Saúde confirma que, somente entre 2015 e 2017, o Brasil registrou mais de 17 mil casos de violência contra pessoas em situação de rua, sendo São Paulo (a

\footnotetext{
${ }^{10}$ Informação disponível em: https://journals.openedition.org/configuracoes/2840. Acesso em: 10/10/2020. Mais informações em: Diário Oficial do Estado de Alagoas, de 13 de julho de 2012.

${ }^{11}$ Informação disponível em: file:///C:/Users/Casa/Downloads/Viola\%C3\%A7\%C3\%B5es-Copa-do-Mundo-1206-14-1.pdf Acesso em: 10/10/2020.

${ }^{12}$ Informação disponível em: https://www.brasildefato.com.br/2020/08/22/frio-intenso-causa-morte-de-cincomoradores-de-rua-em-sp-nos-ultimos-2-dias Acesso em: 10/10/2020.
} 
grande metrópole do país) onde registrou-se o maior número de casos, o número de denúncias foi calculado com base nos registros do Sistema de Informação de Agravos de Notificação (Sinan). A visualização desse dado, com seu recorte de apenas dois anos de denúncias, mostra quão nefasta pode ser as consequências que a imposição que a condição de vida matável acarreta. Ademais, este dado mostra que na cidade mais industrializada e desenvolvida do país a violência contra pessoas em situação de rua é ainda mais alarmante, o que demonstra a força vinculante que o modelo econômico adotado detém para a sistemática de eliminação e violência das pessoas em situação de rua. É importante ressaltar que as violências são causadas não somente pela falta de amparo estatal, mas também pela visão higienista que acomete a sociedade. Isto pode ser traduzido como o ódio e desejo pela morte do outro. Agressões físicas são as mais comuns, elas aconteceram em 92\% dos casos e em 19\% dos casos voltaram a se repetir" ${ }^{13}$. Diante deste cenário, é inegociável indagar: "Como tamanha naturalização de um ódio tão mesquinho foi possível entre nós? Essa é a grande questão brasileira do momento." (SOUZA, 2019, p.112-123). A resposta para esse questionamento começa quando se entende o uso do poder pelo soberano dentro do paradigma do estado de exceção, no qual o necropoder se instaura e se torna a regra.

\section{O decreto presiencial $n^{\circ 7.053 / 09: ~ I n e f i c a ́ c i a ~(i n) c o n s c i e n t e ? ~}$}

O decreto presidencial $\mathrm{n}^{\circ} 7.053 / 09^{14}$ estabelece diretrizes para a política nacional para as pessoas em situação de rua. Tal decreto pode ser visto como o ponto de partida que o Estado utilizou para tentar dar uma resposta, mesmo que de plano, ao problema no país. Porém, este decreto contém algumas incongruências que contribuíram de maneira significativa e basilar para o aumento expressivo da demanda inicial. Por exemplo, um dos pontos não favoráveis é o fato de o decreto tratar a pessoa em situação de rua como se ela própria fosse a responsável por estar naquela situação degradante, já que utiliza critérios subjetivos para identificação do problema. A exemplo, no parágrafo único do seu artigo $1^{\circ}$, são consideradas pessoas em situação de rua: aqueles que fazem parte do grupo heterogêneo que possui em comum a pobreza extrema, ligações familiares interrompidas e a falta de moradia regular e, para tanto, fazem uso de lugares públicos e pontos degradados para morar e autossustentar-se.

\footnotetext{
${ }^{13}$ Informação disponível em: https://www.redebrasilatual.com.br/cidadania/2019/06/populacao-de-rua-violenciaestudo/ Acesso em: 11/10/2020.

${ }^{14}$ Disponível em: http://www.planalto.gov.br/ccivil_03/_ato2007-2010/2009/decreto/d7053.htm

Acesso em 13/10/2020.
} 
Contudo, o decreto em nenhum momento faz referência ou cita problemas coletivos como estrutura basilar para o surgimento da questão, por exemplo, a disparidade econômica e a ausência de políticas públicas realmente eficazes em outras áreas, como no combate à dependência química, saúde mental, álcool ou falta de medidas que promovam mais oportunidades de emprego. Por isso, é fundamental compreender que as políticas públicas voltadas a problemas tão complexos quanto este não restringem o seu âmbito de atuação apenas ao problema por elas tratados, mas sim, atuam de forma mais generalizada com o intuito de sanar determinados pontos que existem fora do problema central, mas que incidem diretamente na situação-problema.

E por mais que o princípio da dignidade da pessoa humana tenha sido demasiadamente utilizado no decreto para fundamentá-lo e dar-lhe base, outro ponto que pode ser entendido como não favorável à mitigação do problema é a divisão de competências das estruturas dos poderes públicos envolvidos, pois, se trata do governo federal impor uma política pública a ser seguida pelos demais entes (estados e municípios) do Estado. Os municípios, por exemplo, devem formular políticas públicas seguindo diretrizes federais, o que soa estranho porque desta forma não resta espaço para os municípios desenvolverem políticas públicas de acordo com as suas especificidades sem que haja a interrupção dos repasses advindos da União para a execução das medidas locais voltadas a este problema (artigo $4^{\circ}$ do decreto presidencial $\mathrm{n}^{\circ} 7.053 / 2009$ ). Com isso, se tem a noção de que projetos idealizados pelos municípios que não seguem a política nacional não serão contemplados com as verbas ou terão o fomento do governo federal cessado, o que produz uma barreira quase intransponível para o atendimento do problema por meios mais pontuais e específicos.

Apesar da formulação deste decreto representar uma inciativa do Estado em tentar resolver o problema das pessoas em situação de rua no Brasil, os erros tanto na identificação do problema (ao utilizar critérios subjetivos para tanto) quanto na divisão das obrigações dos poderes envolvidos (obrigação dos municípios de seguirem as diretrizes federais, afastando a sua característica de segmento estatal mais próximo ao problema) acabaram tornando mais grave esta anomalia social.

Isto pode ser compreendido, como já afirmado, através da análise do número de pessoas em situação de rua no país antes do decreto (mais de 30 mil indivíduos) e após ele (mais de 100 mil indivíduos em 2017). Logo, esta análise representa que o erro estatal no início da formulação da política pública para a solução de um problema tão diverso quanto este gerou não só um aumento exponencial do problema em menos de uma década, mas 
também consequências sociais temerárias a este contingente populacional existente nas ruas, como violações de direitos, banalização da situação degradante a que estas pessoas estão submetidas e violências. Cabe então questionar: A inércia do Estado frente a ineficácia do decreto, visualizada nos números, é intencional? Devemos, e podemos, dizer que a guerra do Estado contra seu inimigo interno é real. Intencionalmente o soberano não garante o mínimo existencial ou a possibilidade de acesso a direitos às pessoas em situação de rua. A morte política desta classe é materializada, não apenas pela direta discriminação e violência sofrida por parte da sociedade, mas também pela sucumbência perante a ausência de meios para autossuficiência.

\section{Pessoas em situação de rua e a necessidade de políticas públicas}

Um censo publicado no site do Senado Federal, cujo a base é a Pesquisa Nacional sobre a População em Situação de Rua do Ministério do Desenvolvimento Social e Combate à Fome de 2008, revela o quão heterogêneo é o grupo existente nas ruas, através deste dado foi possível estabelecer que $82 \%$ são homens, com idades que variam de 22 a 44 anos, 67\% são pardos ou negros. Os números sobre as razões que mais levaram as pessoas a esta condição demonstram que os casos são compostos por 35,5\% de pessoas com problemas de álcool ou drogas, $29,8 \%$ por conta do desemprego, $29,1 \%$ por conta de desavenças familiares e 5,6\% por outros motivos ${ }^{15}$. Portando, no centro da questão está um contingente populacional multifacetado e que está ligado a diversas outras problemáticas sociais, como drogas, desemprego, álcool e relações familiares fragilizadas. Vale ressaltar que, os percentuais mostrados são condizentes a uma pesquisa ocorrida em 2008, ou seja, referente a um ano em que o número de pessoas em situação de rua era mais baixo quando comparado ao número atual (mais de 100 mil indivíduos).

A possibilidade dessas porcentagens terem aumentado no decorrer do tempo ou até mesmo se diluído entre outros grupos sociais, como crianças, mulheres e idosos, é realmente considerável. Não há como precisar, especificamente, a totalidade de grupos heterogêneos que compõem o problema atualmente, haja vista a ausência de levantamentos realizados pelo governo federal sobre a dimensão do problema como um todo. Há tão somente os levantamentos realizados pelos Estados e municípios. Com isso, não há como o Estado isolar

15 Informação disponível em: https://www12.senado.leg.br/noticias/especiais/especial-cidadania/especialcidadania-populacao-em-situacao-de-rua Acesso em: 11/10/2020. 
o seu olhar estratégico, no que diz respeito às suas políticas públicas, sem considerar as claras especificidades que compõem a questão. Assim, a questão da população em situação de rua trata-se da ineficácia dos direitos sociais, de tal forma que não há como implementar estratégias de governo que não atendam todas as especificidades deste problema, o que não pode ser tratado por meio de uma abordagem individualizada da questão. É importante evidenciar que, políticas públicas são ferramentas importantíssimas de gestão em uma sociedade democraticamente estável.

O Governo deve utilizá-las para sanar problemas sociais que pugnam por uma solução urgente, como no caso das pessoas em situação de rua. O reconhecimento do problema público, envolve a elaboração de uma agenda pública adequada ao desenvolvimento da própria política pública, processo político pelo qual se dará sua implementação e execução. Certamente, deve haver o devido monitoramento da política, para que posteriormente, seja possível a verificação da eficácia ou não da mesma. Assim, se necessário for, haverá a reestruturação ou extinção dela. Todos esses procedimentos são indiscutivelmente indispensáveis quando se trata da construção de um caminho que possibilite a mitigação de um problema social. E, quando se trata de um problema tão latente a inobservância desses procedimentos gera consequências negativas maiores, até mesmo, do que o problema em si.

\section{Formulação de políticas que se fazem necessárias frente a tentativa de} materialização de direitos às pessoas em situação de rua

Como pautado anteriormente, a população em situação de rua é composta por um contingente extremamente heterogêneo de sujeitos, dado que existem diferentes indivíduos, de diferentes grupos nesta condição. Ainda observar-se o fato de que todos estes grupos mencionados foram parar nas ruas por conta das mais variadas razões, a por exemplo, desemprego, problemas com drogas, relações familiares fragilizadas, entre outras motivações. Este fato reverbera, e traz à luz, uma questão precípua quando se trata de políticas públicas voltadas para as pessoas em situação de rua: a necessidade de estratégias multifacetadas e ramificadas voltadas para a diminuição da questão. O problema é formado por indivíduos com as mais variadas especificidades, consequentemente, requer-se posicionamentos governamentais condizentes com a pluralidade que envolve o tema, se é que o Estado vislumbra a materialização de direitos para essas pessoas.

Por meio das políticas atuais existentes, o que se constata é que as ações estatais se limitam a um suporte assistencialista, promovendo apenas a manutenção de centros de 
referência especializados para população de rua, a exemplo das secretarias de assistência social dos Estado (Centro Pop). Ou seja, estratégias como essas que apenas acompanham as pessoas em situação de rua, não resolve em nada a saída dessas pessoas da situação de estigmatização e vulnerabilidade. Para tanto, para que haja a saída dessas pessoas dos meandros necropolíticos é necessária a criação e a implementação de métodos eficazes que estabeleçam políticas públicas emancipatórias e que devolvam a estes seres o respeito a sua dignidade enquanto pessoa e que os conduzam para lugares onde há saúde, alimentação, trabalho e direitos constitucionais assegurados e respeitados.

Por isso, a reformulação e a revisitação dos institutos jurídicos e governamentais existentes se faz tão importante, pois são eles que fornecem a base e são os pontos de partida para todas as movimentações governamentais que irão materializar ou dificultar medidas eficazes ou mesmo tornarão obsoletas as soluções adotadas. O decreto $\mathrm{n}^{\circ} 7.053$, por sua vez, comporta elementos que destoam dos caminhos estabelecidos pelo campo das políticas públicas para a diminuição de problemas sociais, e por isso as políticas públicas que atualmente são voltadas para as pessoas em situação de rua são tão inócuas e frágeis. E uma nefasta consequência disto, como já exposto, é a legitimação de violências e violações de direitos contra essas pessoas.

Dentro deste aspecto, não há como haver a diminuição do número de indivíduos que vive nas ruas sem antes haver a admissão de que tanto o decreto presidencial quanto as políticas que dele resultante, são fracas e sem a potência necessária para que a retirada do rótulo de vida matável das pessoas em situação. Essas pessoas no Brasil, enquanto crise social instaurada, são frutos de estruturas sociais não questionadas durante o processo histórico de formação das cidades. "Enfim, tanto causas quanto efeitos recaem apenas sobre os sujeitos e nunca são questionadas as estruturas sociais que permitem a repetição dos comportamentos e das relações que desencadeiam as crises.” (ALMEIDA, 2019, p.198)

Deste modo, é mais que emergencial a criação de novas medidas voltadas à questão, que observem a característica de pluralidade do grupo existente nas ruas e que estabeleçam abordagens multissetoriais do problema, tais como a observância de políticas públicas em outras esferas sociais como: saúde, educação, relações familiares e mercado de trabalho, haja vista que a falha em áreas como essas é um fator importantíssimo para a identificação e formação do grupo existente nas ruas. Desta feita, só quando uma metodologia como esta for implementada é que o rótulo e o estigma conferido à população de rua serão retirados e as 
barreiras que os aprisionam deixarão de existir. Este é um meio em que se vislumbra uma possibilidade de deslegitimação do poder sobre a vida de que detém o soberano.

\section{Conclusão}

Pode-se afirmar que as pessoas em situação de rua são produtos estruturais dos processos históricos do país, a exclusão econômica é o ponto de partida do problema. $\mathrm{O}$ Estado, na figura do soberano, atribui para si o poder sobre a vida. A biopolítica é entendida como a grande inserção da vida natural do ser na governabilidade soberana. O soberano introduz esse contingente existente nas ruas em uma maquinaria estatal que o segrega e mantém à margem das relações sociais, econômicas e políticas existentes. Uma vez que as pessoas em situação de rua representam uma ameaça ao status quo do soberano, este não concebe esses sujeitos como detentores de direitos, e assim os transforma tão somente em vidas matáveis.

Uma política de inimizade é estabelecia entre o Estado e essas pessoas. Em torno das pessoas em situação de rua é construída uma rede de (intencional) estigmatização, opressão e violência, esta rede é tão forte que acaba por arrastar consigo, além das instituições que compõem o Estado, a própria sociedade. Há uma virada, portanto, na classificação da política posta em prática pelo soberano em relação a questão. Sai de cena a biopolítica e entre em jogo a necropolítica. A aversão ao outro torna-se a regra. O desejo pela morte e indiferença em relação as pessoas em situação de rua tornam-se a regra. Regras estas que são voltadas unicamente para a eliminação da ameaça, sua morte política. Como Mbembe (2018, p.71) aduz: “... a noção de biopoder é insuficiente para dar conta das formas contemporâneas de submissão da vida.”. Ou seja, sempre que identificadas problemáticas sociais que detém o poder de interferir em questões políticas, o Estado pode adotar estratégias (diretas ou veladas) que rotulem, segregam e exterminam essas ameaças ao equilíbrio e à manutenção do poder.

Por isso, a manutenção de políticas públicas meramente assistencialistas apenas reafirma que o Estado não está realmente comprometido com a questão das pessoas em situação de rua no país. Elas apenas demonstram que o soberano cercou seu inimigo interno e o está fazendo sucumbir através da indiferença. Assim, a morte política é alcançada, a ameaça é eliminada e o poder do soberano mantido. O poder sobre a vida (biopolítica) ou sobre a morte (necropolítica) encontram uma intersecção na questão das pessoas em situação de rua no Brasil. Ora um, ora outro incide sobre esta problemática social. Mas algo permanece intocável e funcionando das formas mais nefastas imagináveis: o poder, quase que 
inquestionável, que o Estado detém de decidir sobre a vida ou a morte daqueles considerados matáveis, ou seja, não há qualquer obstáculo para o poder soberano agir.

\section{REFERÊNCIAS BIBLIOGRÁFICAS}

AGAMBEN, Giorgio. Homo Sacer: O Poder Soberano e a Vida Nua. $37^{\circ}$ Edição. Belo Horizonte. Boitempo. 2000.

AGAMBEN, Giorgio. Estado de exceção. São Paulo: Boitempo Editorial, 2004.

ALMEIDA Sílvio. Racismo Estrutural. $3^{\circ}$ Reimpressão. São Paulo. Editora Pólen, 2020.

ARENDT, Hannah. Eichmann em Jerusalém. São Paulo: Companhia das Letras, 1963.

FOUCAULT, Michel. Microfísica do poder. 21. Ed. Rio de Janeiro: Record, 2006.

FOUCAULT, Michel. Em defesa da sociedade: curso no Collège de France (1975-1976). $2^{\circ}$ Edição. São Paulo: WMF Martins Fontes, 2010.

FOUCAULT, Michel. História da sexualidade humana. Paris. $1^{\circ}$ Edição. Editora Gallimard, 1976

GOFFMAN, Erving. Estigma-Notas sobre a manipulação da identidade deteriorada. $4^{\circ}$ Edição. LTC. 1981.

GRINOVER, Ada Pellegrini. ASSAGRAD, Gragório. GUSTIN, Miracy. DE LIMA, Paulo César Vicente. LENNACO, Rodrigo. Direitos fundamentais das pessoas em situação de rua. $2^{\circ}$ Edição. EditoraD'Placido. 2016.

MBEMBE. Achille. Necropolítica. $6^{\circ}$ Reimpressão. São Paulo. N-1Edições. 2018.

SITE DO SENADO. Constituição Federal. Disponível em: https://www.senado.leg.br/atividade/const/con1988/con1988_15.12.2016/art_6_.asp Acesso em: 10/07/2020.

SOUZA, Jessé. A elite do Atraso. Rio de Janeiro. Estação Brasil. 2019.

Artigo recebido em: $30 / 10 / 20$

Artigo aprovado em: 05/12/20 